\title{
Mechanism of Action of Essential Oils Extracted from Bamboo (Phyllostachys heterocycla cv. pubescens) Leaves: Chemical Composition and Antimicrobial Activity against Four Food-related Microorganisms
}

Cui Tao, ${ }^{\text {a }}$ Yuanyuan Wang, ${ }^{\mathrm{b}}$ Xinyu Zhang, ${ }^{\mathrm{a}}$ Linzhu Li, ${ }^{\text {a\# }}$ Yi Wu, ${ }^{\mathrm{a}}$ Xue Han, ${ }^{\text {a Xinyi Jiang, }}{ }^{\mathrm{a}}$ and Zhaolin Lv ${ }^{\mathrm{c}, \mathrm{d}, *}$

The antimicrobial activities and potential mechanisms of natural essential oils (EOs) derived from the leaves of Phyllostachys heterocycla cv. pubescens (bamboo) against a broad range of food-borne pathogens, which included Gram-positive (Bacillus subtilis and Staphylococcus aureus) and Gram-negative (Escherichia coli) bacteria and yeast (Saccharomyces cerevisiae), were investigated. The chemical characterization of bamboo leaf essential oils (BLEOs) was determined by gas chromatography-mass spectrometry (GC-MS). Hexadecanoic acid $(19.35 \%)$ and phytol (10.54\%), the antimicrobial ingredients that have been reported in previous studies, were found to be the major components in the BLEOs. According to the antimicrobial tests, Escherichia coli was most sensitive to BLEOs, showing the largest DIZ $(12.77 \pm 0.25 \mathrm{~mm})$ and the lowest MIC $(0.56 \mathrm{mg} / \mathrm{mL})$. In addition, the pathogen growth in the presence of BLEOs at two-times the minimum inhibitory concentration (MIC) revealed that the EOs were bacteriostatic after $12 \mathrm{~h}$ to all tested strains. According to the results from the cellular constituents, the fatty acids profiles, and the atomic force microscope (AFM) observations, the membranes of the treated cells were severely damaged. Therefore, it was concluded that the mechanism of action of BLEOs could be described as a disruption to the pathogen's membrane integrity. The results indicated that the EOs from the leaves of bamboo could be a potential source of antimicrobial agents in the future.

Keywords: Phyllostachys heterocycla cv. pubescens; Essential oils; Antimicrobial activities; Mechanism of action

Contact information: a: School of Biological Sciences and Biotechnology, Beijing Forestry University, Beijing Province 100083 P. R. China; b: School of Tourism and Hotel Management, Shanxi Technology and Business College, Shanxi Province 030000 P. R. China; c: Analysis and Testing Center, Beijing Forestry University, Beijing Province 100083 P. R. China; d: Department of Beijing Key Laboratory of Forest Food Process and Safety, Beijing Forestry University, Beijing, 100083 P. R. China;

* Corresponding author: zhaolinlv@126.com; \# Cui Tao and Linzhu Li are co-first authors

\section{INTRODUCTION}

Despite modern developments in food hygiene and production techniques, foodborne diseases caused by pathogens are still a considerable threat to the human health (Gould et al. 2013). Notable pathogens causing foodborne diseases include Staphylococcus aureus, Listeria monocytogenes, Escherichia coli, Salmonella typhimurium, Vibrio parahaemolyticus, and Clostridium perfringens (Lee et al. 2014), which damage food quality and can also lead to serious health issues to the people that consume the contaminated food. With increasing demand for food that is free from added synthetic 
preservatives, natural, effective, and nontoxic food additives with a broad antimicrobial activity spectrum have garnered much attention (Burt 2004). It has been reported that chitosan-nanocellulose films have the potential to extend shelf life of ground meat (Dehnad et al. 2014). It is important to find more antibacterial agents against food pathogens to improve food safety.

It is known that aromatic plants' essential oils (EOs) and their components have a wide range of applications in ethnomedicine, food preservation, food flavorings, and perfumes and fragrances (Burt 2004; Bakkali et al. 2008). Several investigators have reported about the activities of natural essential oils as antimicrobial agents in food systems, and the essential oils were considered as an additional intrinsic determinant to increase the safety and shelf life of foods (Sagdic et al. 2003; Salgueiro et al. 2010). Phyllostachys heterocycla $c v$. pubescens, which belongs to the family Gramineae (approximately 300 species), is widely distributed in China, Japan, and Southeastern Asian countries (Peng and She 2014); it is one of the most important economic bamboo resources in the world. It has been reported that the EOs from bamboo leaves exhibit various biological activities, such as antioxidant (Kweon et al. 2001; Jin et al. 2011) and antimicrobial (Jin et al. 2011; Tao et al. 2017). However, there are few published investigations that report about the mechanism of the antimicrobial activity of EOs from bamboo leaves. In addition, broad-spectrum antimicrobial activities of bamboo leaf essential oils (BLEOs) still need to be studied in detail. Thus, the objectives of this work were to investigate the antimicrobial effect of BLEOs on major food-related microorganisms, and to determine the mechanism of antimicrobial activity of BLEOs.

\section{EXPERIMENTAL}

\section{Materials}

Plant materials and chemicals

Bamboo leaves from Phyllostachys heterocyla cv. pubescens were collected in Nanping City, Fujian Province, China. The leaf samples were sent to the College of Biological Sciences and Biotechnology, Beijing Forestry University (Beijing, China) for species confirmation. Nutrient agar (NA) and yeast peptone dextrose agar (YPDA) were purchased from Beijing Aoboxing Bio-tech Co., Ltd. (Beijing, China). All reagents used in the experiments were of analytical grade.

\section{Microbial strains and culture}

The antimicrobial activities of the EOs were tested on four food-related microorganisms, which included two Gram-positive bacteria (Staphylococcus aureus CICC 10384 and Bacillus subtilis CICC 20034), one Gram-negative bacteria (Escherichia coli CICC 23845), and one yeast (Saccharomyces cerevisiae CICC 1346). These strains were provided by the College of Biological Sciences and Biotechnology, Beijing Forestry University (Beijing, China), and were cultured at $37{ }^{\circ} \mathrm{C}$ in NA for bacteria and at $28{ }^{\circ} \mathrm{C}$ in YPDA for the yeast.

\section{Methods}

Extraction of BLEOs

The bamboo leaves were ground and extracted in a modified EOs extraction device described by Lv et al. (2010). A schematic diagram of the device is displayed in Fig 1. 
Briefly, the dried bamboo leaves were ground and hydrodistilled (liquid-to-solids ratio of 25:1) for $4.5 \mathrm{~h}$. During the heating, the steam containing the EOs was condensed. Then, the condensed water droplets were passed through $n$-hexane, and essential oils distilled in the condensed water were extracted into $n$-hexane. The water after $n$-hexane extraction was recirculated back to the distillation flask. Finally, the $n$-hexane was collected and dried over anhydrous sodium sulfate. The dried $n$-hexane was evaporated using a rotary evaporator (Manufacturer, City, Country), where the temperature $(T)$ was $<40^{\circ} \mathrm{C}$ under a vacuum, to yield the extracted EOs. The BLEOs obtained were stored in dark vials at $4{ }^{\circ} \mathrm{C}$ that were tightly closed until needed.

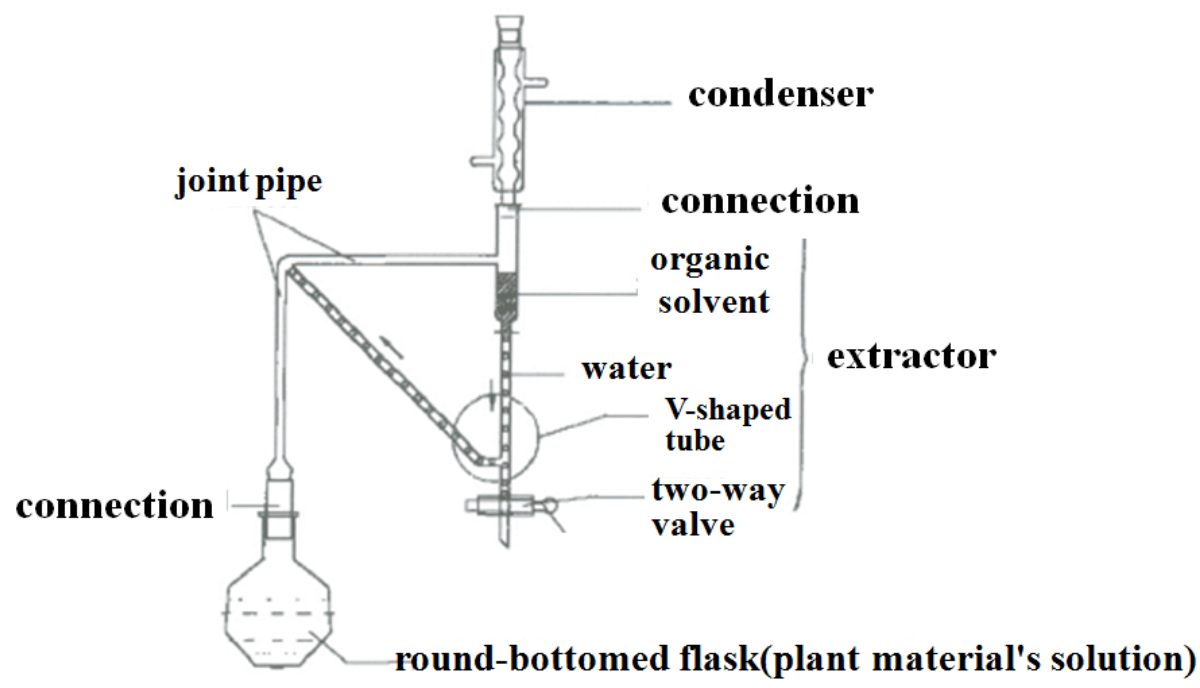

Fig. 1. The schematic diagram of the device used for the extraction of BLEOS

\section{Chemical characterization analysis of the BLEOs}

Chemical characterization of the BLEOs was carried out according Tao's method (Tao et al. 2017) using gas chromatography-mass spectrometry (GC-MS; GCMS-QP2010 Ultra; Shimadzu, Kyoto, Japan). The device was equipped with an Rtx-5MS quartz capillary column $(30 \mathrm{~m} \times 0.25 \mathrm{~mm} \times 0.25 \mu \mathrm{m})$. The oven temperature was programmed to the following schedule: $60{ }^{\circ} \mathrm{C}$ for $2 \mathrm{~min}$, raised to $220{ }^{\circ} \mathrm{C}$ at a rate of $3{ }^{\circ} \mathrm{C} / \mathrm{min}$, ramped to a rate of $15{ }^{\circ} \mathrm{C} / \mathrm{min}$ to $280{ }^{\circ} \mathrm{C}$, and held at $280{ }^{\circ} \mathrm{C}$ for $10 \mathrm{~min}$. The injector and detector temperatures were $280{ }^{\circ} \mathrm{C}$. The extracted essential oils $(0.4 \mu \mathrm{L})$ were manually injected at a split mode of 15:1. High-purity helium was used as the carrier gas at a flow rate of 1 $\mathrm{mL} / \mathrm{min}$. The mass selective detector was operated in electron-impact ionization (EI) mode with a mass scan range from $\mathrm{m} / \mathrm{z} 33$ to 500 at $70 \mathrm{eV}$. The BLEOs constituents were qualitative compared to the published mass spectra data, as well as to the National Institute of Standards and Technology (NIST) mass spectra library data. The components of the BLEOs were determined as a relative percentage of the total oil by peak area.

\section{Agar punching diffusion assay}

The essential oils were completely dissolved in $n$-hexane at a concentration of 36.00 $\mathrm{mg}$ EOs/mL $n$-hexane. Antimicrobial tests were then performed by the agar punching diffusion method. A suspension $(100 \mu \mathrm{L})$ that contained $10^{5}$ to $10^{6} \mathrm{CFU} / \mathrm{mL}$ of microbes was swabbed onto the surface of sterile NA or YPDA medium using a sterile cotton swab. A plastic straw with a diameter of $5 \mathrm{~mm}$ was then inserted into the inoculated agar, and 30 
$\mu \mathrm{L}$ of essential oils were added by micropipette. The diameter of inhibition zone (DIZ) was measured after $24 \mathrm{~h}$ of incubation at $37^{\circ} \mathrm{C}$ for bacteria, and $48 \mathrm{~h}$ of incubation at $28^{\circ} \mathrm{C}$ for yeast; $n$-hexane was used as a negative control. The tests were performed in triplicate.

\section{Minimum inhibitory concentration (MIC)}

The MIC was determined according to the method described by Lee et al. (2014) with minor modifications. Two-fold serial dilutions of BLEOs were prepared in melted NA or YDPA medium in sterile test tubes; the final concentrations of the samples ranged from 0.56 to $18 \mathrm{mg} \mathrm{EOs} / \mathrm{mL}$ medium. The test tubes were inoculated with $100 \mu \mathrm{L}$ of the test pathogen suspension to yield a microbe concentration of $10^{5}$ to $10^{6} \mathrm{CFU} / \mathrm{mL}$. The mixtures were poured into plates and then inoculated as described earlier. The MIC values were reported as the lowest concentration of the BLEOs that inhibited microbial growth. A control test was also performed that contained the inoculated medium with only $n$-hexane.

\section{Growth curve determination}

The growth curve assay was determined in accordance with the method described by Muroi and Kubo (1993) with some modifications. Briefly, the cultivation with the EOs at two times the MIC value was executed in the same way as the above assay. The cultures were incubated at $37{ }^{\circ} \mathrm{C}$ for bacteria and $28{ }^{\circ} \mathrm{C}$ for yeast. The samples were shaken on a rotary shaker at $120 \mathrm{rpm}$. At selected time intervals, the absorbance was measured at a wavelength of $600 \mathrm{~nm}\left(\mathrm{OD}_{600 \mathrm{~nm}}\right)$ for bacteria and $560 \mathrm{~nm}\left(\mathrm{OD}_{560 \mathrm{~nm}}\right)$ for yeast.

\section{Release of cellular materials}

The release of cellular materials was measured and assessed in accordance with previous literature reports with some modifications (Oussalah et al. 2006; Xu et al. 2010; Moshayedi et al. 2013). In brief, the tested strains were cultured to a logarithmic growth phase and then centrifuged (at $8000 \mathrm{rpm}$ for $20 \mathrm{~min}$ ) to collect the microbial cells. These were then washed three times with sterile water and then resuspended in $0.1 \mathrm{M}$ phosphate buffer saline (PBS ( $\mathrm{pH}$ 7.2)). The essential oils were added into the cell suspensions to procure the required concentration of two times the MIC value. After incubation for $6 \mathrm{~h}$ at $37^{\circ} \mathrm{C}$ for bacteria (or $28^{\circ} \mathrm{C}$ for yeast), $20 \mathrm{~mL}$ of each sample was collected and centrifuged at $12,000 \mathrm{rpm}$ for $5 \mathrm{~min}$. The supernatants obtained were analyzed to determine the concentrations of proteins and sugar in accordance with the method described by Xu et al. (2010). In addition, $3 \mathrm{~mL}$ of the supernatant was gathered; the ultraviolet (UV) absorption at $260 \mathrm{~nm}$ of the supernatant was recorded to measure the concentration of nucleic acids released by the cellular material.

\section{Analysis of membrane fatty acid composition}

The cultured broths of each microorganism were centrifuged for $15 \mathrm{~min}$ at 5000 $\mathrm{rpm}$, the solids were washed three times, and the washed solids were resuspended in $0.1 \mathrm{M}$ phosphate buffer saline (PBS ( $\mathrm{pH} 7.0)$ ). After the addition of BLEOs and incubation for 3 $\mathrm{h}$, the cell pellets were harvested and subjected to membrane fatty acid extraction. Extractions of fatty acids from the cellular materials were performed as described by Lv et al. (2011) with some modifications. Lipid samples were transmethylated for analysis of their acyl groups as fatty acid methyl esters (FAME) via a GC-MS (GCMS-QP2010 Ultra, Shimadzu, Kyoto, Japan) analysis. The oven temperature was programmed to the following schedule: initial temp at $120^{\circ} \mathrm{C}$ for $2 \mathrm{~min}$, then raised up to $200^{\circ} \mathrm{C}$ at a rate of $3{ }^{\circ} \mathrm{C} / \mathrm{min}$, then ramped at an increment of $5{ }^{\circ} \mathrm{C} / \mathrm{min}$ to $250^{\circ} \mathrm{C}$ for $2 \mathrm{~min}$, and raised up to $280^{\circ} \mathrm{C}$ at a 
rate of $8{ }^{\circ} \mathrm{C} / \mathrm{min}$, finally holding for $10 \mathrm{~min}$ at $280{ }^{\circ} \mathrm{C}$. The injector and detector temperatures were $280{ }^{\circ} \mathrm{C}$. The EOs $(1 \mu \mathrm{L})$ were manually injected at a split mode of $20: 1$. High-purity helium was used as the carrier gas at a flow rate of $1 \mathrm{~mL} / \mathrm{min}$. The mass selective detector was operated in electron-impact ionization (EI) mode with a mass scan range from $\mathrm{m} / \mathrm{z} 33$ to 500 at $70 \mathrm{eV}$.

\section{Atomic force microscope (AFM)}

The effects of BLEOs on the microorganism's cell surface were examined by AFM (Bruker Multimode 8 AFM with Nanoscope V Controller, Bruker Corp., Karlsruhe, Germany). Cells were first collected by centrifuging the microbial suspension $\left(10^{5}\right.$ to $10^{6}$ $\mathrm{CFU} / \mathrm{mL}$ ) at $4000 \mathrm{rpm}$ for $10 \mathrm{~min}$; the solids were washed with $0.1 \mathrm{M} \mathrm{PBS} \mathrm{(pH} \mathrm{7.2)} \mathrm{three}$ times and resuspended in $0.1 \mathrm{M}$ PBS ( $\mathrm{pH}$ 7.2). The treated microbial suspension samples were incubated at a concentration of two times the MIC of essential oils for $3 \mathrm{~h}$. After the incubation, the cells were collected, washed twice, and immobilized overnight in the PBS that contained $2.5 \%$ glutaraldehyde. The control samples (without essential oils) and treatment samples were both applied on a freshly cleaved mica surface, which was followed by air-drying. All samples were prepared at the same time and were exposed to the same environmental conditions. The AFM images were obtained in tapping mode using a silica probe (NP-S20; Veeco Instruments, Plainview, NY, USA) with the settings of 512 pixels/line and $1.5 \mathrm{~Hz}$ scan rate (Ziaee et al. 2010; Campos et al. 2012).

\section{Statistical analysis}

All values were expressed as means \pm standard deviation (SD) of three experiments. The Student's $t$-test was used for the statistical analysis, and a value of $\rho<0.05$ was considered statistically significant. The photographs of AFM and figures were only the representative. Microsoft Excel 2016 software (Redmond, WA, USA), Origin 8.5 software (Origin Lab, Northampton, MA, USA), and SPSS 19.0 software package (SPSS Inc., Chicago, IL, USA) were employed for the data analysis.

\section{RESULTS AND DISCUSSION}

\section{Chemical Composition of the EOs}

Qualitative and quantitative analyses of the volatile compounds in the essential oils were determined via GC-MS; the results are presented in Table 1. In total, 39 components were identified, which accounted for $95.83 \%$ of the total detected constituents in the essential oils from the leaves of $P$. heterocyla $c v$. pubescens. Hexadecanoic acid (19.35\%), phytol $(10.54 \%)$, and pentacosane $(9.89 \%)$ were the major components, followed by lauric acid $(4.65 \%)$, 4-hydroxy-2-methylacetophenone $(4.27 \%)$, tetratriacontane $(4.16 \%)$, isophytol (3.43\%), $\alpha$-Ionone (3.23\%), dibutyl phthalate $(2.65 \%), 6,10,14$-trimethyl-2pentadecane ketone (2.64\%), eicosane (2.47\%), and damascenone (2.09\%). Other identified compounds that were present were at concentrations lower than $2 \%$. Organic acids, alcohols, hydrocarbons, and ketones were the main constituents. The profile obtained in this study was very similar to previous results reported by Tao et al. (2017) with only slight differences in concentrations. Conversely, Jin et al. (2011) reported that the main components comprising the essential oils of bamboo leaves were cis-3-hexenol $(27.11 \%)$, 3-methyl-2-butanol (6.8\%), (E)-2-hexenal (5.32\%), and hexadecanoic acid (3.19\%); these 
reported literature values are very different than the chemical compositions obtained from this study. These differences might arise from geographical origins, cultivation varieties, seasonal variations, and extraction methods, as well as genetic differences of bamboo species (Perry et al. 1999).

Table 1. Chemical Composition of BLEOs

\begin{tabular}{|c|c|c|c|c|}
\hline No. & Compound & $\begin{array}{c}\text { Molecular } \\
\text { Formula }\end{array}$ & $\begin{array}{l}\text { Retention } \\
\text { Index }\end{array}$ & $\begin{array}{l}\text { Concentration } \\
\text { (Peak Area \%) }\end{array}$ \\
\hline 1 & Hexanol & $\mathrm{C}_{6} \mathrm{H}_{14} \mathrm{O}$ & 860 & 1.01 \\
\hline 2 & Leaf alcohol & $\mathrm{C}_{6} \mathrm{H}_{12} \mathrm{O}$ & 868 & 1.75 \\
\hline 3 & Cyclohexanol & $\mathrm{C}_{6} \mathrm{H}_{12} \mathrm{O}$ & 908 & 0.34 \\
\hline 4 & 5,6-Diethyl-1,3-cyclohexadiene & $\mathrm{C}_{10} \mathrm{H}_{16}$ & 1005 & 0.67 \\
\hline 5 & 2,3-Dihydrobenzofuran & $\mathrm{C}_{8} \mathrm{H}_{8} \mathrm{O}$ & 1036 & 0.78 \\
\hline 6 & 1-Nonen-4-ol & $\mathrm{C}_{9} \mathrm{H}_{18} \mathrm{O}$ & 1068 & 1.29 \\
\hline 7 & Benzeneacetaldehyde & $\mathrm{C}_{8} \mathrm{H}_{8} \mathrm{O}$ & 1081 & 1.67 \\
\hline 8 & Nonanal & $\mathrm{C}_{9} \mathrm{H}_{18} \mathrm{O}$ & 1104 & 0.8 \\
\hline 9 & Menthone & $\mathrm{C}_{10} \mathrm{H}_{18} \mathrm{O}$ & 1148 & 0.53 \\
\hline 10 & Safranal & $\mathrm{C}_{10} \mathrm{H}_{14} \mathrm{O}$ & 1186 & 0.3 \\
\hline 11 & 4-Ethylbenzaldehyde & $\mathrm{C}_{9} \mathrm{H}_{10} \mathrm{O}$ & 1195 & 0.45 \\
\hline 12 & 2,6-Dimethyl-1-cyclohexen-1-yl acetate & $\mathrm{C}_{10} \mathrm{H}_{16} \mathrm{O}_{2}$ & 1208 & 1.76 \\
\hline 13 & Nonanoic acid & $\mathrm{C}_{9} \mathrm{H}_{18} \mathrm{O}_{2}$ & 1272 & 0.37 \\
\hline 14 & 2-Undecenal & $\mathrm{C}_{11} \mathrm{H}_{20} \mathrm{O}$ & 1311 & 0.34 \\
\hline 15 & 4-Hydroxy-2-methylacetophenone & $\mathrm{C}_{9} \mathrm{H}_{10} \mathrm{O}_{2}$ & 1363 & 4.27 \\
\hline 16 & Geranylacetone & $\mathrm{C}_{13} \mathrm{H}_{22} \mathrm{O}$ & 1420 & 1.24 \\
\hline 17 & $\alpha$-Ionone & $\mathrm{C}_{13} \mathrm{H}_{20} \mathrm{O}$ & 1429 & 3.23 \\
\hline 18 & Damascenone & $\mathrm{C}_{13} \mathrm{H}_{18} \mathrm{O}$ & 1440 & 2.09 \\
\hline 19 & $\beta$-Ionone & $\mathrm{C}_{13} \mathrm{H}_{20} \mathrm{O}$ & 1457 & 1.02 \\
\hline 20 & Ionone epoxide & $\mathrm{C}_{13} \mathrm{H}_{20} \mathrm{O}_{2}$ & 1479 & 0.85 \\
\hline 21 & Lauric acid & $\mathrm{C}_{12} \mathrm{H}_{24} \mathrm{O}_{2}$ & 1570 & 4.65 \\
\hline 22 & Dicyclohexyl ketone & $\mathrm{C}_{13} \mathrm{H}_{22} \mathrm{O}$ & 1576 & 0.53 \\
\hline 23 & 6,10,14-trimethyl-2-pentadecane ketone & $\mathrm{C}_{18} \mathrm{H}_{36} \mathrm{O}$ & 1754 & 2.74 \\
\hline 24 & Myristic acid & $\mathrm{C}_{14} \mathrm{H}_{28} \mathrm{O}_{2}$ & 1769 & 0.86 \\
\hline 25 & Isophytol & $\mathrm{C}_{20} \mathrm{H}_{40} \mathrm{O}$ & 1899 & 3.43 \\
\hline 26 & Farnesyl acetone & $\mathrm{C}_{18} \mathrm{H}_{30} \mathrm{O}$ & 1902 & 1.58 \\
\hline 27 & Hexadecanoic acid & $\mathrm{C}_{16} \mathrm{H}_{32} \mathrm{O}_{2}$ & 1968 & 19.35 \\
\hline 28 & Stearaldehyde & $\mathrm{C}_{18} \mathrm{H}_{36} \mathrm{O}$ & 1999 & 1.16 \\
\hline 29 & Eicosane & $\mathrm{C}_{20} \mathrm{H}_{42}$ & 2009 & 2.47 \\
\hline 30 & Dibutyl phthalate & $\mathrm{C}_{16} \mathrm{H}_{22} \mathrm{O}_{4}$ & 2037 & 2.65 \\
\hline 31 & Phytol & $\mathrm{C}_{20} \mathrm{H}_{40} \mathrm{O}$ & 2045 & 10.54 \\
\hline 32 & Methyl oleate & $\mathrm{C}_{19} \mathrm{H}_{36} \mathrm{O}_{2}$ & 2085 & 2.03 \\
\hline 33 & Geranyl linalool & $\mathrm{C}_{20} \mathrm{H}_{34} \mathrm{O}$ & 2192 & 0.77 \\
\hline 34 & Pentacosane & $\mathrm{C}_{25} \mathrm{H}_{52}$ & 2506 & 9.89 \\
\hline 35 & Hexacosane & $\mathrm{C}_{26} \mathrm{H}_{54}$ & 2606 & 0.89 \\
\hline 36 & 1-Hexacosanol & $\mathrm{C}_{26} \mathrm{H}_{54} \mathrm{O}$ & 2848 & 0.57 \\
\hline 37 & Tetratriacontane & $\mathrm{C}_{34} \mathrm{H}_{70}$ & 3401 & 4.16 \\
\hline 38 & Tetracosane & $\mathrm{C}_{24} \mathrm{H}_{50}$ & 3501 & 0.95 \\
\hline 39 & Hexatriacontane & $\mathrm{C}_{36} \mathrm{H}_{74}$ & 3600 & 1.85 \\
\hline & Total identified components & & & 95.83 \\
\hline
\end{tabular}

Hexadecanoic acid (19.35\%), phytol (10.54\%), and pentacosane (9.89\%) were the three major components in the BLEOs, and have been reported to have antimicrobial activity in previous studies (Karthikeyan et al. 2014; Lee et al. 2016). These literature 
findings corroborate the reported observations of this study regarding the antimicrobial efficacy of the EOs from the leaves of P. heterocyla $c v$. pubescens.

\section{DIZ, MIC, and Growth Curves of the BLEOs}

The antimicrobial activities of the BLEOs were tested on four different microorganisms that were selected based on their relevance as food contaminants. The DIZ and the MIC values of the essential oils are presented in Table 2. The results showed that the essential oils had certain antimicrobial effects on all of the tested microorganisms. The DIZ values of the oil on the tested microorganisms ranged from $8.77 \pm 0.25 \mathrm{~mm}$ to 12.77 $\pm 0.25 \mathrm{~mm}$, and MIC values ranged from 0.56 to $2.25 \mathrm{mg}$ oil $/ \mathrm{mL}$ medium. Among these tested microorganisms, the essential oils exhibited the greatest antimicrobial effect against the Gram-negative bacteria E. coli, with both the highest DIZ value $(12.77 \mathrm{~mm})$ and the lowest MIC value ( $0.56 \mathrm{mg}$ oil $/ \mathrm{mL}$ medium). The inhibition zones of the essential oils on the test microorganisms showed a marked correlation with MIC values $(p<0.05)$. Comparing the DIZ and MIC values, E. coli was considerably the most sensitive microorganism; this was followed by $B$. subtilis, S. cerevisiae, and $S$. aureus, which showed similar susceptibility as was indicated by the same MIC value $(2.25 \mathrm{mg}$ oil $/ \mathrm{mL}$ medium).

The effects of the BLEOs on the growth rate of the tested microorganisms, as measured by the $\mathrm{OD}_{600 \mathrm{~nm}}$ for the bacterial strains and by the OD $560 \mathrm{~nm}$ for the yeast strain, are shown in Fig. 1. For all the studied food pathogens, the treatment resulted in an appreciable decrease in the maximum growth rate in the log phase when compared to the control. Moreover, all of the samples treated with EOs had visibly lower stationary phase levels than the control, with E. coil showing the greatest reduction.

The results obtained indicated that the EOs from bamboo leaves had strong inhibitory effects to all of the tested food-borne pathogens, which included Gram-positive stains, Gram-negative strains, and yeast. The antimicrobial effects of the EOs derived from P. heterocyla cv. pubescens leaves to food-borne strains, such as Staphylococcus aureus, Escherichia coli, Bacillus subtilis, Pseudomonas fluorescens, and Flavobacterium columnare, have been reported by some recent investigations (Jin et al. 2011; Tao et al. 2017).

These literature reports are congruent with the findings of this study. The growth curves of the microorganisms determined by measuring the viable cell counts indicated that the BLEOs had a negative effect on the cell viability of all the tested strains. E. coil was the most sensitive microorganism, which was in accordance with the DIZ and MIC results. Similar results were also obtained in Guo's work that the Gram-negative bacteria E. coil showed the lowest MIC and MBC values when acted upon by Amomum tsaoko essential oil (Guo et al. 2017).

The Gram-negative bacteria are generally considered less sensitive than the Grampositive ones to the essential oil (Gill and Holley 2006), while several studies have also founded that some Gram-positive bacteria are less or equally sensitive to Gram-positive bacteria. Therefore, the antibacterial activity of essential oil probably depended on the type of essential oil more than the bacteria (Dorman et al. 2000). The exposure of microorganisms to EOs mainly affected the logarithmic growth phase. It was inferred that the normal division and reproduction of cells was inhibited by the BLEOs. 
Table 2. DIZ and MIC Values with the Essential Oils from the Leaves of $P$. heterocyla $\mathrm{cv}$. pubescens Against the Tested Microorganisms

\begin{tabular}{|c|c|c|}
\hline Test Microorganisms & DIZ $(\mathrm{mm})$ & MIC $(\mathrm{mg}$ Oil $/ \mathrm{mL}$ Medium $)$ \\
\hline Bacillus subtilis & $11.97 \pm 0.29^{\mathrm{a}}$ & 1.12 \\
\hline Staphylococcus aureus & $8.77 \pm 0.25^{\mathrm{b}}$ & 2.25 \\
\hline Escherichia coli & $12.77 \pm 0.25^{\mathrm{a}}$ & 0.56 \\
\hline Saccharomyces cerevisiae & $9.77 \pm 0.46^{\mathrm{b}}$ & 2.25 \\
\hline
\end{tabular}

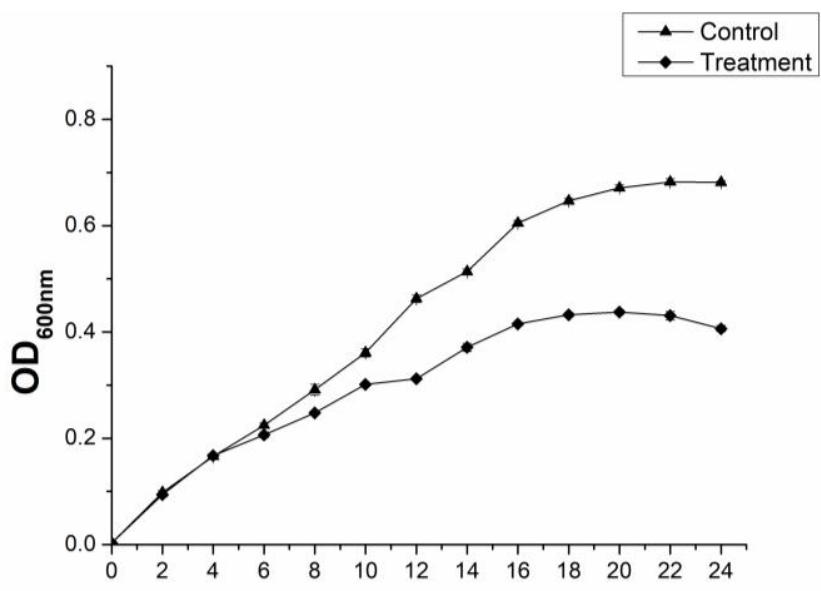

A

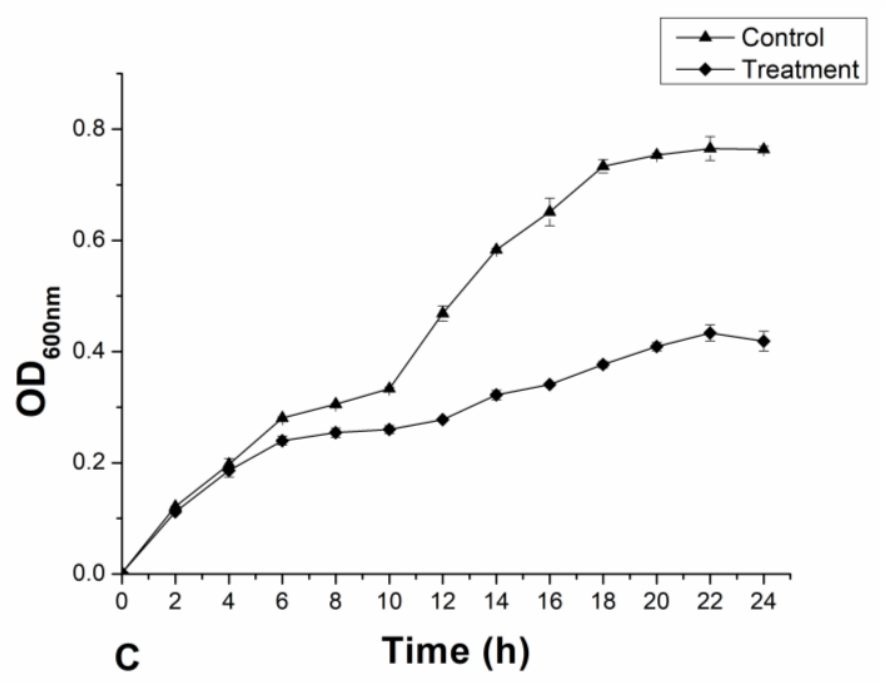

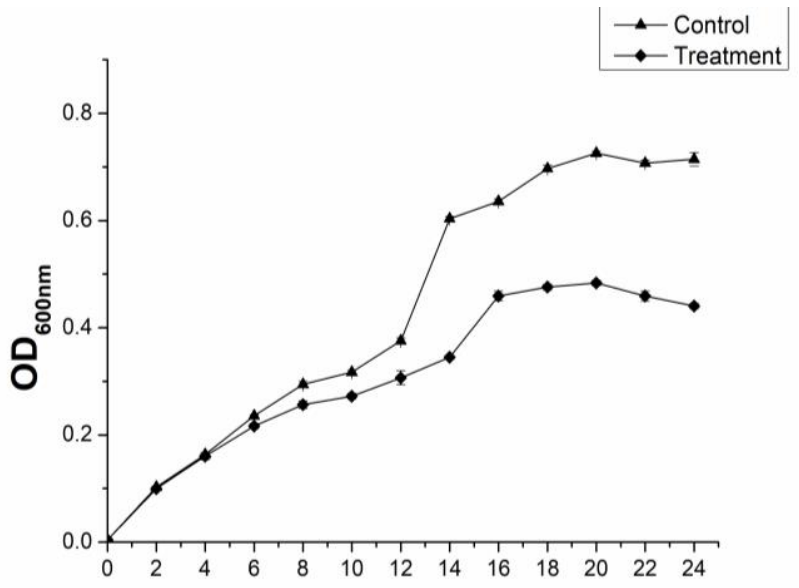

B Time (h)

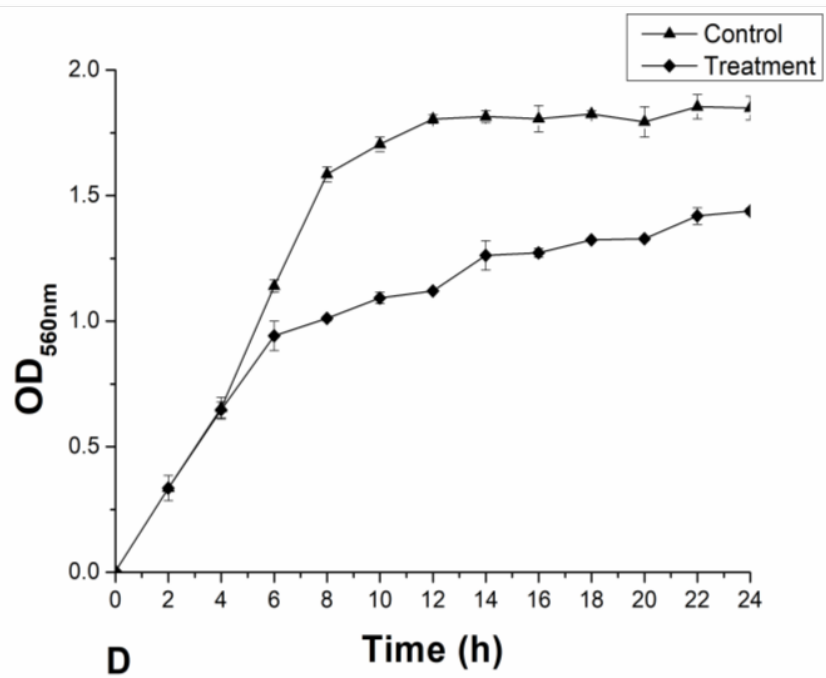

Fig. 2. The effect of BLEOs on the growth curves of the tested microorganisms at two times the MIC value for: (A) B. subtilis; (B) S. aureus; (C) E. coli; and (D) S. cerevisiae

\section{Antimicrobial Mechanism of BLEOs}

To further study the antimicrobial mode of the BLEOs, the major cell constituents and the profiles of the membranes' fatty acids were examined to note changes to the permeability and integrity of cell membranes. An AFM analysis was used to determine the surface characteristics of the microorganisms. Furthermore, AFM imaging is a highly suitable tool for the study of bacteria, making this technique extremely advantageous for the antibacterial effect. (Gaboriaud et al. 2005). 
Table 3. Effect of the Essential Oils on Release of Cell Constituents by Tested Microorganisms

\begin{tabular}{|c|c|c|c|c|c|c|c|c|c|c|c|c|}
\hline & \multicolumn{4}{|c|}{ Protein $(\mu \mathrm{g} / \mathrm{mL})$} & \multicolumn{4}{|c|}{ Sugar $(\mu \mathrm{g} / \mathrm{mL})$} & \multicolumn{4}{|c|}{ Cell Constituents $\left(\mathrm{OD}_{260}\right)$} \\
\hline Treatment & B. subtilis & S. a & E. coli & $\begin{array}{c}S . \\
\text { cerevisiae }\end{array}$ & B. subtilis & S. aureus & E. coli & $\begin{array}{c}S . \\
\text { cerevisiae }\end{array}$ & B. subtilis & S. aureus & E. coli & $\begin{array}{c}S . \\
\text { cerevisiae }\end{array}$ \\
\hline Control & $46.6 \pm 2.1 \mathrm{a}$ & $41.0 \pm$ & $55.4 \pm$ & $50.7 \pm 3.3^{a}$ & $29.6=$ & 28.2 & 33.1 & $\begin{array}{c}992.4 \pm \\
13.5^{\mathrm{a}}\end{array}$ & & & & $\begin{array}{c}0.113 \pm \\
0.004^{\mathrm{a}}\end{array}$ \\
\hline $2 \times \mathrm{MIC}$ & $54.4 \pm 3.6^{b}$ & $59.5 \pm 1.8$ & $68.6 \pm 4.2^{b}$ & $71.5 \pm 4.3^{b}$ & $35.8 \pm 2.2^{b}$ & $33.2 \pm 3.0^{\mathrm{b}}$ & $38.2 \pm 2.8^{b}$ & $\begin{array}{c}1131.1 \pm \\
18.3^{\mathrm{b}} \pm\end{array}$ & $\begin{array}{l}0.277 \pm \\
0.005^{\mathrm{b}}\end{array}$ & $\begin{array}{l}0.188 \pm \\
0.004^{\mathrm{b}}\end{array}$ & $\begin{array}{c}0.349 \pm \\
0.006^{\mathrm{b}}\end{array}$ & $\begin{array}{c}0.222 \pm \\
0.006^{\mathrm{b}}\end{array}$ \\
\hline
\end{tabular}

Values represent mean values of three independent replicates (with \pm standard deviations). Different superscripted letters within a column indicate statistically significant differences between the two means $(p<0.05)$ via the Tukey's paired comparison statistical test; $2 \times$ MIC stands for twice the MIC concentration of BLEOs.

Table 4. The Effect of BLEOs on the Fatty Acids Profiles of the Tested Microorganisms

\begin{tabular}{|c|c|c|c|c|c|c|c|c|}
\hline & \multicolumn{2}{|c|}{ E. coli } & \multicolumn{2}{c|}{ S. aureus } & \multicolumn{2}{c|}{ B. subtilis } & \multicolumn{2}{c|}{ S. cerevisiae } \\
\hline FAME* $^{*}$ & Control & Treated & Control & Treated & Control & Treated & Control & Treated \\
\hline C10:0 & ND $^{\mathrm{b}}$ & ND & ND & ND & ND & ND & $5.22 \pm 0.113$ & $4.275 \pm 0.077$ \\
\hline C12:0 & $3.51 \pm 0.02^{\mathrm{a}}$ & $6.63 \pm 0.2917$ & ND & $3.635 \pm 0.007$ & ND & $7.48 \pm 0.064$ & $4.47 \pm 0.467$ & $7.145 \pm 0.120$ \\
\hline C14:1 & ND & ND & ND & ND & ND & ND & $1.61 \pm 0.035$ & $1.645 \pm 0.035$ \\
\hline C14:0 & $6.47 \pm 0.057$ & $6.92 \pm 0.304$ & ND & $4.92 \pm 0.014$ & ND & $5.24 \pm 0.106$ & $2.95 \pm 0.707$ & $3.87 \pm 0.757$ \\
\hline C15:0 & $2.12 \pm 0.014$ & $2.30 \pm 0.106$ & ND & $1.675 \pm 0.007$ & $9.22 \pm 0.057$ & $4.06 \pm 0.085$ & ND & $0.645 \pm 0.007$ \\
\hline C16:1 & $10.95 \pm 0.085$ & $5.27 \pm 0.240$ & ND & $4.195 \pm 0.007$ & ND & ND & $34.80 \pm 2.451$ & $29.44 \pm 2.345$ \\
\hline C16:0 & $45.58 \pm 1.280$ & $60.37 \pm 1.435$ & $56.41 \pm 4.27$ & $59.54 \pm 2.234$ & $57.30 \pm 2.34$ & $55.82 \pm 0.900$ & $32.67 \pm 3.405$ & $33.49 \pm 3.340$ \\
\hline C17:1 cis & $5.48 \pm 0.042$ & $2.30 \pm 0.106$ & ND & $1.925 \pm 0.007$ & ND & ND & ND & ND \\
\hline C18:2 & ND & ND & ND & $2.805 \pm 0.104$ & ND & $2.99 \pm 0.064$ & ND & $1.68 \pm 0.102$ \\
\hline C18:1 & $6.17 \pm 0.049$ & $6.06 \pm 0.269$ & ND & $6.575 \pm 0.242$ & ND & $7.15 \pm 0.141$ & $11.15 \pm 1.233$ & $11.37 \pm 1.220$ \\
\hline C18:0 & $19.73 \pm 1.004$ & $10.17 \pm 2.758$ & $43.59 \pm 4.27$ & $14.73 \pm 2.305$ & $33.48 \pm 1.24$ & $17.27 \pm 1.358$ & $7.15 \pm 0.922$ & $6.45 \pm 0.655$ \\
\hline
\end{tabular}

* FAME is fatty acid methyl ester; a Percentage values, means of duplicate measurements (with \pm standard deviations); ${ }^{\mathrm{b}}$ Not detected 


\section{Release of cellular materials}

The release of cellular material from the four tested strains into the medium was measured and assessed to determine whether the cells' membranes were damaged after being treated by the BLEOs. The major cellular constituents included proteins and sugar; the UV absorbance at $260 \mathrm{~nm}$ was also measured, which is regarded as an index of cell lysis (Kasi et al. 2010). The results of these measurements are presented in Table 3 . The results showed that after the addition of twice the MIC concentration of BLEOs for $6 \mathrm{~h}$, the release of cell constituents significantly increased $(p<0.05)$ when compared to the control under all conditions. The increase in the measured values indicated that the microorganism exposure to the BLEOs resulted in the damage of cells' membranes and appreciable cellular leakage.

\section{Changes of membrane fatty acids profiles}

It has been shown that the microbial cells would regulate the membrane's fluidity by changing its fatty acid chain length and the fatty acid composition, when being in the attack from the antimicrobial compounds (Pasqua et al. 2006). Therefore, the profile alterations to membrane fatty acids profiles were examined from the cellular extracts after microorganism's exposure to BLEOs for $3 \mathrm{~h}$. The extracted fatty acids were analyzed by GC-MS once they were derivatized to their corresponding FAMEs. The major fatty acids were identified and their concentrations were determined in the extracts of the control and the treatment for each microorganism; the results are presented in Table 4. The results showed that the presence of BLEOs affected the lipid profiles of all microorganisms examined, both in the quantity and the fatty acid types. As shown in Table 4, the fatty acid compositions of $S$. aureus and B. subtilis were strongly affected by the presence of BLEOs, especially in the fatty acid types. The $E$. coli cells, after treatment by BLEOs, showed a significant increase in its lipid profile $(p<0.05)$ of saturated $\mathrm{C} 16$ fatty acids, and a decrease of the saturated $\mathrm{C} 18$ fatty acids. However, the fatty acids profile of the yeast (S. cerevisiae) after treatment showed little alteration when compared to the control.

\section{AFM observations}

Application of AFM for spatial resolution surface imagining has been recommended as a useful tool for gaining insight across the range from subcellular structures to multi-cellular assemblies (Kaminskyj and Dahms 2008). The AFM method is theoretically capable of higher resolution imaging than other microscopes and delivering quantitative results. Morphological characterizations of the microorganisms of both the untreated (control) and essential oils treated are presented in Fig. 2. The left column of graphs (control) displayed typical rod-shaped cells for B. subtilis and E. coli, and coccishaped cells for $S$. aureus and $S$. cerevisiae. The images of the samples treated with essential oils at a concentration of twice the MIC concentration for $3 \mathrm{~h}$ are shown in the right column of Fig. 2.

When compared to the corresponding control, all the images showed notable differences in cell structure; treated microorganisms exhibited cellular collapse and rougher surfaces. These observations were confirmed by the measurement of the membrane roughness (Table 5). 
Table 5. Measured AFM Parameter Roughness from the Tested Microorganisms

\begin{tabular}{|c|c|c|}
\hline Tested Microorganisms & $R_{\mathrm{q}}(\mathrm{nm})$ & SD \\
\hline B. subtilis & 21.54 & 6.88 \\
\hline B. subtilis-treated & 33.43 & 2.10 \\
\hline S. aureus & 28.22 & 3.31 \\
\hline S. aureus-treated & 43.88 & 8.95 \\
\hline E. coli & 21.18 & 8.01 \\
\hline E. coli-treated & 43.66 & 7.88 \\
\hline S. cerevisiae & 10.77 & 2.09 \\
\hline S. cerevisiae-treated & 56.32 & 3.90 \\
\hline
\end{tabular}

$R_{q}$ represents the root mean square roughness and SD represents the standard deviation

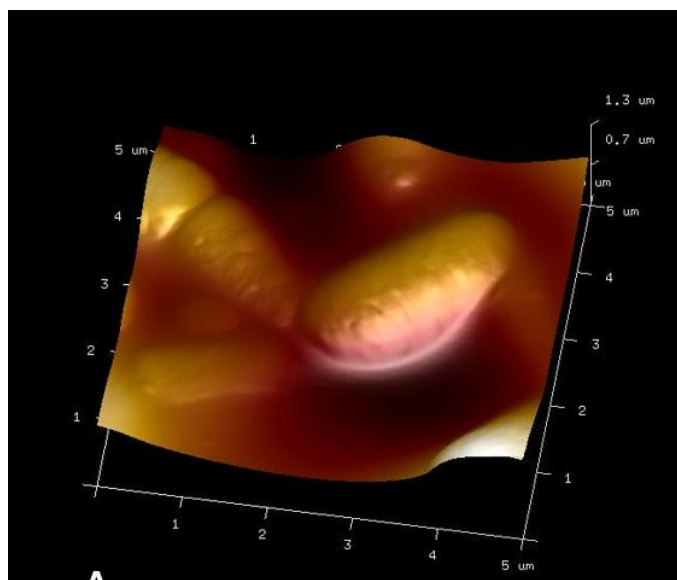

A

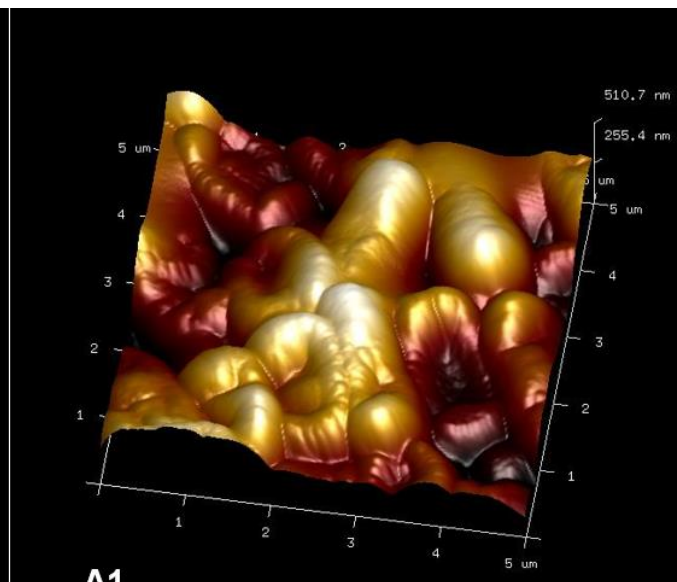

A1

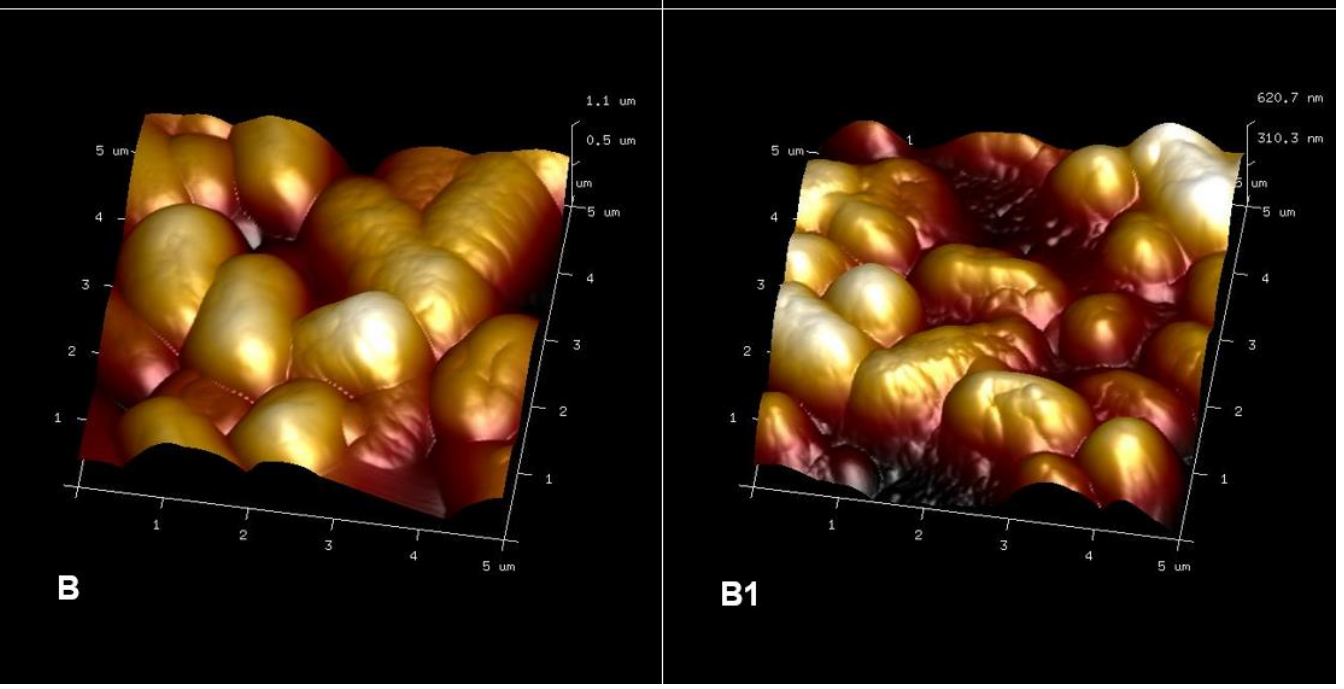

Fig. 3 (part 1). AFM images (in tapping mode) of the effect of BLEOs on cell morphology for: untreated (A) B. subtilis, (B) S. aureus, (C) E. coli, and (D) S. cerevisiae; and treated with essential oils (A1) B. subtilis, (B1) S. aureus, (C1) E. coli, and (D1) S. cerevisiae; treatment was performed with essential oils at two times the MIC concentration for $3 \mathrm{~h}$ 

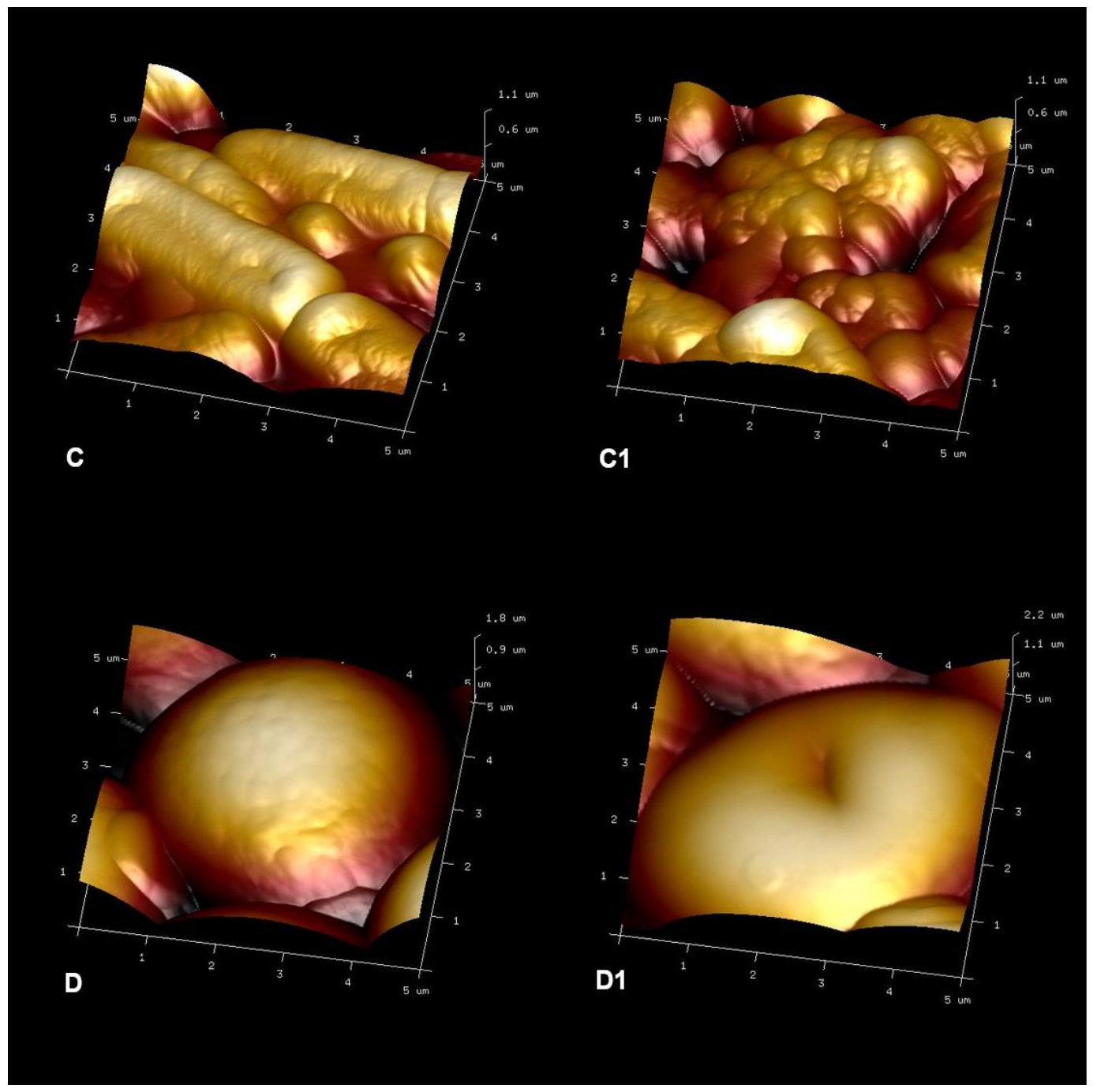

Fig. 3. (part 2). AFM images (in tapping mode) of the effect of BLEOs on cell morphology for: untreated (A) B. subtilis, (B) S. aureus, (C) E. coli, and (D) S. cerevisiae; and treated with essential oils (A1) B. subtilis, (B1) S. aureus, (C1) E. coli, and (D1) S. cerevisiae; treatment was performed with essential oils at two times the MIC concentration for $3 \mathrm{~h}$

Significant variations in the roughness values were found between the BLEO treated and BLEO untreated cells of all the tested strains. Nevertheless, there were also some undamaged cells in the tested strains. In all the cases tested, the treated E. coli was observed to be more deformed, which indicated cellular rupture and lysis of the membranes (Fig. 2C1).

The results presented here showed that the release of constituents from the microorganisms increased and the profile of the fatty acids changed when the cells were treated with BLEOs. This observation indicated an increase in cell membrane permeability. Some authors have suggested that the distortion of the cell walls and cytoplasmic membranes causes the expansion and destabilization of the membranes, which increases membrane permeability that results in the leakage of various vital intracellular constituents, leading to cell death (Lv et al. 2011). These findings indicated that irreversible damage to the cytoplasmic membranes occurred after exposure to BLEOs, which was supported by the AFM observations. In addition, some studies reported that the active ingredients of the 
EOs might bind to the cell wall surfaces and then penetrate the phospholipid bilayer of the cytoplasmic membrane (Rhayour et al. 2003). However, to determine the accurate action site that the BLEOs impart damage to cells, deeper research is needed. Additionally, different changes to the fatty acids profiles occurred between the bacteria and the yeast, which could be inferred that BLEOs exhibited antimicrobial activities toward the bacteria and the yeast due to different mechanisms of action. The AFM images showed notable morphological alterations appeared in the cell walls and membranes of all the tested microorganisms. Similar cellular damage has been reported for various kinds of microorganisms when exposed to different essential oils (Diao et al. 2014; Hu et al. 2017). In line with the findings of cellular leakage and with the fatty acid profiles, the EOs were likely to interact with the cell walls that results in the disruption of the cell walls and the consequent release of intracellular contents. However, it is possible that other sites of action besides the cytoplasmic membrane exist. Therefore, further work is necessary to fully understand the mechanisms involved.

\section{CONCLULSIONS}

1. The chemical composition of bamboo leaves EOs were identified, and hexadecanoic acid (19.35\%) and phytol (10.54\%) were the major constituents.

2. The bamboo leaves EOs possessed promising antimicrobial activities to four selected foodborne pathogens.

3. According to MIC and DIZ tests, Escherichia coli was most sensitive to BLEO, showing the largest DIZ $(12.77 \pm 0.25 \mathrm{~mm})$ and the lowest MIC $(0.56 \mathrm{mg} / \mathrm{mL})$.

4. The antimicrobial action of BLEOs is thought to be related to how the EOs interact with the cell surfaces to damage membrane integrity, which leads to the leakage of the intracellular contents until the cell lysis.

\section{ACKNOWLEDGEMENTS}

This work was financially supported by a project from the Science and Technology Research of Beijing Forestry University (Project No. 2015-01), and a program for Research and Development of Botanical Novel Green Preservative, National Science-Technology Support Plan Projects (Project No. 2015BAD16B01).

\section{REFERENCES CITED}

Bakkali, F., Averbeck, S., Averbeck, D., and Idaomar, M. (2008). "Biological effects of EOs - A review," Food Chem. Toxicol. 46, 446-475. DOI: 10.1016/j.fct.2007.09.106

Burt, S. (2004). "Essential oils: Their antibacterial properties and potential applications in foods - A review," Int. J. Food Microbiol. 94(3), 223-253. DOI:

10.1016/j.ijfoodmicro.2004.03.022

Campos, D. A., Ribeiro, A. C., Costa, E. M., Fernandes, J. C., Tavaria, F. K., Araruna, F. B., Eiras, C., Eaton, P., Leite, J. R. S. A., and Pintado, M. M. (2012). "Study of 
antimicrobial activity and atomic force microscopy imaging of the action mechanism of cashew tree gum," Carbohyd. Polym. 90(1), 270-274.

DOI: 10.1016/j.carbpol.2012.05.034

Dehnad, D., Mirzaei, H., Diomeh, Z. E., Jafari, S. M., and Dadashi S. (2014). "Thermal and antimicrobial properties of chitosan-nanocellulose films for extending shelf life of ground meat," Carbohyd. Polym. 109, 148-154. DOI:

10.1016/j.carbpol.2014.03.063

Diao, W., Hu, Q., Zhang, H., and Xu, J. (2014). "Chemical composition, antibacterial activity and mechanism of action of essential oil from seeds of fennel (Foeniculum vulgare Mill.)," Food Control. 35, 109-116. DOI: 10.1016/j.foodcont.2013.06.056

Dorman, H. J. D., and Deans, S. G. (2000). "Antimicrobial agents from plants: Antibacterial activity of plant volatile oils, " Journal of Applied Microbiology. 88(2), 308-316. DOI: 10.1046/j.1365-2672.2000.00969.x

Gaboriaud, F., Bailet, S., Dague, E., and Jorand, F. (2005). "Surface, structure and nanomechanical properties of Shewanella putrefaciens bacteria at two $\mathrm{pH}$ values (4 and 10) determined by atomic force microscopy," J. Bacteriol. 187(11), 3864-3868. DOI: $10.1128 / \mathrm{JB} .187 .11 .3864-3868.2005$

Gill, A. O., and Holley, R. A. (2006). "Disruption of Escherichia coli, Listeria monocytogenes and Lactobacillus sakei cellular membranes by plant oil aromatics," International Journal of Food Microbiology. 108(1), 1-9. DOI:

10.1016/j.ijfoodmicro.2005.10.009

Gould, L. H., Walsh, K. A., Vieira, A. R., Herman, K., Williams, I. T., Hall, A. J., and Cole, D. (2013). "Surveillance for foodborne disease outbreaks - United States, 19982008," Morbidity and Mortality Weekly Report: Surveillance Summaries 62(2), 1-34.

Guo, N., Zang, Y. P., Cui, Q., Gai, Q. Y., Jiao, J., Wang, W., Zu, Y. G., and Fu, Y. J. (2017). "The preservative potential of Amomum tsaoko essential oil against E. coli, its antibacterial property and mode of action," Food Control. 75, 236-245. DOI: 10.1016/j.foodcont.2016.12.013

Hu, Y., Zhang, J., Kong, W., Zhao, G., and Yang, M. (2017). "Mechanisms of antifungal and anti-aflatoxigenic properties of essential oil derived from turmeric (Curcuma longa L.) on Aspergillus flavus," Food Chem. 220, 1-8. DOI: 10.1016/j.foodchem.2016.09.179

Jin, Y. C., Yuan, K., and Zhang, J. (2011). "Chemical composition, and antioxidant and antimicrobial activities of essential oil of Phyllostachys heterocycla cv. pubescens varieties from China," Molecules 16(5), 4318-4327. DOI: 10.3390/molecules 16054318

Kaminskyj, S. G. W., and Dahms, T. E. S. (2008). "High spatial resolution surface imaging and analysis of fungal cellas using SEM and AFM," Micron. 39, 349-361. DOI: 10.1016/j.micron.2007.10.023

Karthikeyan, S. C., Karthikeyan, S., Velmurugan, M., Birdilla, S., Donio, M., Babu, M., and Citarasu, T. (2014). "Studies on the antimicrobial potential and structural characterization of fatty acids extracted from Sydney rock oyster Saccostrea glomerata," Ann. Clin. Microb. Anti. 13(1), 332-343. DOI: 10.1186/s12941-0140057-X

Kasi, P. D., Arif Nisha, S., Ravi, S., and Pandian, S. (2010). "Eugenol (an essential oil of clove) acts as an antibacterial agent against Salmonella typhi by disrupting the cellular membrane," J. Ethnopharmacol. 130(1), 107-115. DOI: 10.1016/j.jep.2010.04.025 
Kweon, M., Hwang, H., and Sung, H. (2001). "Identification and antioxidant activity of novel chlorogenic acid derivatives from bamboo (Phyllostachys edulis)," J. Agr. Food Chem. 49(10), 4646-4655. DOI: 10.1021/jf010514x

Lee, S., Kim, K., Lim, S., and Ahn, D. (2014). "Antibacterial mechanism of Myagropsis myagroides extract on Listeria monocytogenes," Food Control 42(42), 23-28. DOI: 10.1016/j.foodcont.2014.01.030

Lee, W., Woo, E., and Lee, D. G. (2016). "Phytol has antibacterial property by inducing oxidative stress response in Pseudomonas aeruginosa," Free Radical Research 50(12), 1309-1318. DOI: 10.1080/10715762.2016.1241395

Lv, F., Liang, H., Yuan, Q., and Li, C. (2011). "In vitro antimicrobial effects and mechanism of action of selected plant essential oil combinations against four foodrelated microorganisms," Food Res. Int. 44(9), 3057-3064. DOI: 10.1016/j.foodres.2011.07.030

Lv, Z. L., Zhang, B. L., Yao, Y. H., Qin J., Zhan H. N., inventors (2010). "A modified device that extracting the essential oil of bamboo leaves," CN. Patent 101693853A.

Moshayedi, S., Shahraz, F., Schaffner, D., Khanlarkhani, A., Shojaee-Aliabadi, S., Shahnia, M., and Khaksar, R. (2013). "In vitro control of Enterococcus faecalis by Zataria multilfolira Boiss, Origanum vulgare L. and Mentha pulegium essential oils," J. Food Safety 33(3), 327-332. DOI: doi.org/10.1111/jfs.12056

Muroi, H., and Kubo, I. (1993). "Combination effects of antibacterial compounds in green tea flavor against Streptococcus mutans," J. Agr. Food Chem 41(7), 1102-1105. DOI: 10.1021/jf00031a017

Oussalah, M., Caillet, S., and Lacroix, M. (2006). "Mechanism of action of Spanish oregano, Chinese cinnamon, and savory essential oils against cell membranes and walls of Escherichia coli 0157:H7 and Listeria monocytogenes," J. Food Protect. 69(5), 1046-1055. DOI: 10.4315/0362-028X-69.5.1046

Pasqua, R. D., Hoskins, N., Betts, G., Mauriello, G. (2006). "Changes in membrane fatty caids composition of microbial cells induced by addiction of thymol, carvacrol, limonene, cinnamaldehyde, and eugenol in the growing media," J. Agr. Food Chem. 54(7), 2745-2749. DOI:10.1021/jf0527221

Peng, P., and She, D. (2014). "Isolation, structural characterization, and potential applications of hemicelluloses from bamboo: A review," Carbohyd. Polym. 112 701720. DOI: 10.1016/j.carbpol.2014.06.068

Perry, N. B., Anderson, R. E., Brennan, N. J., Douglas, M. H., Heaney, A. J., McGimpsey, J. A., and Smallfield, B. M. (1999). "Essential oils from dalmatian sage (Salvia officinalis L.): Variations among individuals, plant parts, seasons, and sites," J. Agr. Food Chem. 47(5), 2048-2054. DOI: 10.1021/jf981170m

Rhayour, K., Bouchikhi, T., Tantaoui-Elaraki, A., Sendide, K., and Remmal, A. (2003). "The mechanism of bactericidal action of oregano and clove essential oils and of their phenolic major components on Escherichia coli and Bacillus subtilis," J. Essent. Oil Res. 15(4), 356-362. DOI: 10.1080/10412905.2003.9712144

Sagdic, O., Karahan, A., Ozcan, M., and Ozkan, G. (2003). "Note: Effect of some spice extracts on bacterial inhibition," Food Sci. Technol. Int. 9(9), 353-358. DOI: $10.1177 / 108201303038976$

Salgueiro, L., Martins, A. P., and Correia, H. (2010). "Raw materials: The importance of quality and safety. A review," Flavour Frag. J. 25(5), 253-271. DOI:

10.1002/ffj.1973 
Tao, C., Wu, J., Liu, Y., Liu, M., Yang, R., and Lv, Z. (2017). "Antimicrobial activities of bamboo (Phyllostachys heterocycla cv. pubescens) leaf essential oil and its major components," Eur. Food Res. Technol. 244(3), 881-891. DOI: 10.1007/s00217-0173006-Z

Xu, J., Hu, Q., Wang, X., Luo, J., Liu, Y., and Tian, C. (2010). "Changes in the main nutrients, phytochemicals, and antioxidant activity in yellow corn grain during maturation," J. Agr. Food Chem. 58(9), 5751-5756. DOI: 10.1021/jf100364k.

Ziaee, Z., Qian, L., Guan, Y., Fatehi, P., and Xiao, H. (2010). "Antimicrobial/antimold polymer-grafted starches for recycled cellulose fibers," J. Biomat. Sci.-Polym. E. 21(10), 1359-1370. DOI: 10.1163/092050609X12517190417795

Article submitted: September 2, 2018; Peer review completed: November 11, 2018; Revised version received: December 16, 2018; Accepted: December 20, 2018; Published: January 7, 2019.

DOI: 10.15376/biores.14.1.1419-1434 